\title{
Tarefas Investigativas de Geometria Dinâmica e Saberes do Professor que Ensina Matemática: uma Revisão de Literatura
}

\section{Dynamic Geometry Investigative Tasks and Mathematics' Teacher Knowledge: a Literature Review}

\author{
Rafael Enrique Gutiérrez Araujo*ab; Vinícius Pazuch ${ }^{\mathrm{b}}$
}

${ }^{a}$ Asociación Aprender en Red. Venezuela

${ }^{b}$ Universidade Federal do ABC. SP, Brasil.

*E-mail: rafael.gutierrez0593@gmail.com

\begin{abstract}
Resumo
Este artigo reporta a revisão de literatura de uma pesquisa sobre os saberes mobilizados por um grupo de professores que ensinam matemática, em um contexto formativo, quando se engajam na elaboração de tarefas investigativas de geometria dinâmica para o ensino de geometria. $\mathrm{O}$ objetivo do artigo é analisar as contribuições da literatura para a elaboração de tarefas investigativas de geometria dinâmica como atividade especifica do professor que ensina matemática, com foco nos saberes mobilizados nessa atividade. Para tal, optou-se por uma estratégia de busca de informação baseada na definição de dois eixos temáticos, quais sejam, "Dynamic Geometry" - GeoGebra (uma vez que interessam tarefas elaboradas com esse software) e "Teacher Knowledge"-Mathematics. Cada expressão anterior indica um descritor de busca, posteriormente inserido em três bases de dados (Redalyc, SciELO e Web of Science). O processo de busca resultou em 21 estudos, analisados e relacionados entre si conforme o método de revisão metassintese. Os resultados obtidos mostram, entre outros aspectos, que as tarefas de cunho investigativo são predominantes nos cenários de ensino de geometria que incorporam Software de Geometria Dinâmica (SGD). Porém, esses resultados também revelam a ausência de pesquisas focadas na maneira em que professores que ensinam matemática elaboram esse tipo de tarefa e mobilizam saberes para tal fim, constituindo essa ausência um campo de pesquisa sobre esse tema.
\end{abstract}

Palavras-chave: Formação de professores. Software GeoGebra. Educação Básica.

\begin{abstract}
This article reports a literature review about mathematics teacher's knowledge mobilized from a teacher group in a formative context, when they are engaged in the elaboration of investigative dynamic geometry tasks' elaboration for teaching geometry. The objective of the article is to analyze the contributions from the literature regarding the elaboration of investigative dynamic geometry tasks, as a specific activity of teaches mathematics teacher, focusing on the mobilized knowledge in this activity. For that, we opted for an information search strategy based on the definition of two thematic axes, namely, "Dynamic Geometry" - GeoGebra (since the tasks developed with this software are interesting) and "Teacher Knowledge" - Mathematics, being that each previous sentence (separated by a hyphen) indicates a search descriptor, later inserted in three databases (Redalyc, SciELO and Web of Science). The search process resulted in 21 studies, analyzed and related to each other according to the meta-synthesis review method. The results obtained show, among other aspects, that investigative tasks are the predominant type of task in geometry teaching scenarios that incorporate Dynamic Geometry Software (SGD). However, these results also reveal the absence of research focused on the way in which mathematics teachers elaborate this type of tasks and mobilize knowledge for this purpose, the former constituting a research field on this topic.
\end{abstract}

Keywords: Teacher Education. GeoGebra Software. Middle and High School.

\section{Introdução}

A mobilização de saberes docentes na elaboração de tarefas de geometria dinâmica é uma temática emergente na pesquisa em Educação Matemática. Particularmente, estudos como o de Powell \& Pazuch (2016) têm evidenciado saberes docentes decorrentes da resolução de tarefas de geometria dinâmica propostas em cursos de formação continuada em ambientes online de aprendizagem. No referido estudo, são reveladas características procedimentais e teóricas - construção, interação, significado matemático, questionamento, engajamento, linguagem matemática e feedback - a serem consideradas na elaboração das tarefas citadas.

Por sua vez, Trocki \& Hollebrands (2018) usam a noção de prompt, que remete à elaboração de questões norteadoras relacionadas a uma construção prévia em geometria dinâmica.
Os autores explicitam que essas questões requerem uma resposta verbal ou escrita. Ademais, elas podem demandar ações tecnológicas, como desenho, construção, medição ou manipulação de objetos matemáticos produzidos previamente. Compreende-se que essas questões podem ser exploratórias ou investigativas.

Em consonância com os referidos autores, Gutiérrez \& Pazuch (2019) incorporam essas noções procedimentais e teóricas na elaboração de tarefas de geometria dinâmica de cunho exploratório e investigativo. Essas tarefas visam a oportunizar momentos de discussão e de reflexão em processos de formação inicial ou continuada de professores que ensinarão/ensinam matemática na Educação Básica.

Diante da necessidade de apontar evidências sobre a elaboração de tarefas investigativas de geometria dinâmica e sobre a forma em que professores mobilizam saberes para 
tal fim, realizou-se a revisão de literatura apresentada neste documento. Em particular, o objetivo do artigo é analisar as contribuições da literatura para a elaboração de tarefas investigativas de geometria dinâmica como atividade específica do professor que ensina matemática.

Especificamente, realizou-se uma metassíntese (Fiorentini \& Crecci, 2012), isto é, uma modalidade da metanálise qualitativa (Fiorentini \& Lorenzato, 2012). Basicamente, a metassíntese de um conjunto de pesquisas consiste:

[...] na produção de evidências qualitativas (isto é, pequenas sínteses interpretativas) que são extraídas de cada pesquisa acerca de um problema, fenômeno ou foco de estudo para, a seguir, serem relacionadas (confrontadas ou contrastadas), produzindo outras interpretações que permitem compor uma nova síntese de interpretações. (Fiorentini \& Coelho, 2012, p. 1056)

Em termos de organização do artigo, apresentam-se a seguir três seções. Primeiro, são abordados os processos metodológicos. Depois, são discutidos os resultados da metassíntese. Por fim, expõem-se as conclusões.

\section{Processos Metodológicos}

Para iniciar a revisão de literatura, estabeleceu-se como estratégia de busca de informação a definição de diferentes eixos vinculados com o tema do estudo. De acordo com o tema desta pesquisa, foram consideradas as áreas da geometria dinâmica e os saberes do professor que ensina matemática. A partir disso, foram definidos estes dois eixos de busca: (i) "Dynamic Geometry" - GeoGebra; e (ii) "Teacher Knowledge" - Mathematics. Cada um dos itens, separados por hífen, indica um descritor de busca.

A definição dos estudos que seriam utilizados foi realizada em 3 etapas: busca, organização e exclusão. A primeira etapa, realizada entre os meses de julho e agosto do ano 2018, consistiu na busca das produções científicas de interesse em 3 bases de dados (Redalyc, SciELO e Web of Science), publicadas no período de 2008 a $2017^{1}$. Em se tratando de 3 bases de dados e 2 eixos, foram realizadas 6 buscas no total, obtendo como resultado 308 produções científicas nas áreas temáticas citadas acima. Na Tabela 1, ilustra-se o total de produções encontradas por cada base de dados.

Tabela 1 - Total de produções científicas encontradas na etapa de busca

\begin{tabular}{|l|c|c|c|c|}
\hline \multicolumn{1}{|c|}{ Eixos da Busca } & Redalyc & SciELO & WOF & Total \\
\hline $\begin{array}{l}\text { "Dynamic Geometry" } \\
\text { - GeoGebra }\end{array}$ & 26 & 04 & 30 & 60 \\
\hline $\begin{array}{l}\text { "Teacher Knowledge" } \\
\text { - Mathematics }\end{array}$ & 88 & 21 & 139 & 248 \\
\hline & & & & $\mathrm{T}=308$ \\
\hline
\end{tabular}

Fonte Dados da pesquisa.
Na segunda etapa, foram organizados os resultados obtidos na etapa anterior. Para tal, elaborou-se um instrumento como o ilustrado no Quadro 1, em que foram inseridos os metadados (título, revista, ano, autores e resumo) das 308 produções. É importante ressaltar que nessa etapa de organização ainda não foram buscados os documentos por extenso das 308 produções encontradas, dado que esse número devia passar pelo filtro descrito na terceira etapa.

Quadro 1 - Instrumento para o fichamento dos metadados dos artigos

\begin{tabular}{|c|l|l|l|l|c|}
\hline \multicolumn{2}{|c|}{ Base de Dados: } & \multicolumn{3}{c|}{ Total de Artigos: } & $\begin{array}{c}\text { Período da } \\
\text { Busca: }\end{array}$ \\
\hline Título & Revista & Ano & Autores & Resumo & $\begin{array}{c}\text { Critérios de } \\
\text { Exclusão }\end{array}$ \\
\hline $\begin{array}{c}\text { Título do } \\
\text { artigo \# 1 }\end{array}$ & & & & & \\
\hline$\ldots$ & & & & & \\
\hline $\begin{array}{c}\text { Título do } \\
\text { artigo \# } \mathrm{n}\end{array}$ & & & & & \\
\hline
\end{tabular}

Fonte: Elaborado pelos autores (2020).

Nota: *

$\mathrm{Na}$ terceira etapa, foram excluídas produções que não eram de interesse da revisão. Por esse motivo, foi acrescentada ao Quadro 1 uma coluna para indicar os critérios de exclusão, aplicados após revisar o título e o resumo de cada produção. De acordo com o tema do estudo, foram excluídas aquelas produções relacionadas: (i) à formação inicial de professores; (ii) a contextos de ensino nos Anos Iniciais; (iii) à aprendizagem de estudantes; (iv) à abordagem de conteúdos específicos distintos de geometria; (v) a áreas de conhecimento diferentes do ensino de matemática; e (vi) ao uso de Software de Geometria Dinâmica (SGD) distinto do GeoGebra. Também foram excluídas produções em idiomas diferentes do inglês, do português e do espanhol. A exclusão das produções que não cumpriram os critérios estabelecidos reduziu o número inicial a 21 artigos científicos, os quais constituíram o corpus da revisão ${ }^{2}$.

\section{Resultados da Revisão ${ }^{3}$}

Nesta seção, são apresentados os resultados da metassíntese dos 21 artigos do corpus constituído. Eles estão organizados pela revisão dos dois eixos mencionados: (i) "Dynamic Geometry" - GeoGebra; e (ii) "Teacher Knowledge" Mathematics.

\subsection{Metassíntese do Eixo 1: "Dynamic Geometry" - GeoGebra}

Dos 21 artigos da revisão, 8 são do primeiro eixo,

1 Dado que a etapa de busca foi realizada antes do término de 2018, optou-se por não considerar as produções científicas publicadas nesse ano.

$2 \mathrm{Na}$ realidade, foram 22 os artigos estabelecidos após a etapa de exclusão. Porém, o texto \# 22 foi finalmente excluído pela impossibilidade de encontrálo em sua versão PDF.

3 Considera-se imperativo aclarar que esses resultados respondem às escolhas realizadas. Tem-se consciência de que, pelo filtro aplicado no procedimento de busca, não se consideraram produções de outro tipo (dissertações de mestrado, teses de doutorado, etc.) relacionadas à temática abordada neste artigo e que bem teriam aportado elementos importantes aos resultados da revisão realizada. 
categorizados em 3 grupos temáticos (Quadro 2). A partir dessa categorização, apresentam-se as sinteses interpretativas dos 8 artigos, destacando seus objetivos, referenciais teóricos, metodologia empregada, resultados e conclusões. Finalmente, relatam-se as sinteses integrativas dos textos de cada categoria, destacando convergências e divergências.

Quadro 2. Temáticas dos artigos do Eixo 1

\begin{tabular}{|l|l|l|l|}
\hline \multicolumn{1}{|c|}{ Temática do Artigo } & \multicolumn{1}{|c|}{ Autor(es) do Artigo } & \multicolumn{1}{c|}{ Subfoco Temático } & \multicolumn{1}{c|}{ Contexto Investigativo } \\
\hline \multirow{4}{*}{$\begin{array}{c}\text { 1. Propostas de atividades que } \\
\text { envolvem o uso de SGD }\end{array}$} & Scaglia \& Götte (2008) & $\begin{array}{l}\text { Desenvolvimento profissional } \\
\text { de professores }\end{array}$ & $\begin{array}{l}\text { Formação continuada de } \\
\text { professores }\end{array}$ \\
\cline { 2 - 4 } & $\begin{array}{l}\text { Bastos, Poffal \& Meneghetti } \\
(2015)\end{array}$ & $\begin{array}{l}\text { Tarefas para o ensino de } \\
\text { geometria }\end{array}$ & $\begin{array}{l}\text { Ensino de geometria na } \\
\text { Educação Básica }\end{array}$ \\
\cline { 2 - 4 } & Lognoli (2017) & $\begin{array}{l}\text { Estratégias pedagógicas de } \\
\text { ensino de geometria }\end{array}$ & Pesquisa teórica \\
\hline \multirow{4}{*}{$\begin{array}{l}\text { 2. Potencialidades dos SGD } \\
\text { ensino de geometria }\end{array}$} & $\begin{array}{l}\text { Santos-Trigo \& Reyes- } \\
\text { Rodríguez (2016) }\end{array}$ & $\begin{array}{l}\text { Tarefas para o ensino de } \\
\text { geometria }\end{array}$ & $\begin{array}{l}\text { Formação continuada de } \\
\text { professores }\end{array}$ \\
\cline { 2 - 5 } & Poon \& Wong (2017) & $\begin{array}{l}\text { Recursos digitais para o ensino } \\
\text { de geometria }\end{array}$ & $\begin{array}{l}\text { Ensino de geometria na } \\
\text { Educação Básica }\end{array}$ \\
\hline \multirow{3}{*}{$\begin{array}{l}\text { 3. Aplicação de referenciais } \\
\text { teóricos que envolvem o uso } \\
\text { de SGD }\end{array}$} & Alqahtani \& Powell (2016) & $\begin{array}{l}\text { Apropriação de ambientes } \\
\text { colaborativos de geometria } \\
\text { dinâmica }\end{array}$ & $\begin{array}{l}\text { Formação continuada de } \\
\text { professores }\end{array}$ \\
\cline { 2 - 5 } & $\begin{array}{l}\text { Gómez-Chacón, Romero \& } \\
\text { García (2016) }\end{array}$ & $\begin{array}{l}\text { Relações entre cognição e afeto } \\
\text { no raciocínio geométrico }\end{array}$ & $\begin{array}{l}\text { Ensino de geometria na } \\
\text { Educação Básica }\end{array}$ \\
\hline
\end{tabular}

Fonte: Dados da pesquisa.

O grupo temático \# 1 relaciona os estudos de Scaglia \& Götte (2008), Bastos, Poffal \& Meneghetti (2015) e Lognoli (2017). Esses artigos têm em comum propostas de atividades que envolvem o uso de $S G D$, com ênfase em experiências de desenvolvimento profissional de professores de matemática, tarefas matemáticas e estratégias pedagógicas para o ensino de geometria na Educação Básica.

Scaglia \& Götte (2008) apresentam uma proposta de formação continuada de professores de matemática para o uso do software GeoGebra por meio da descrição da resolução de um conjunto de tarefas investigativas com um grupo de docentes dessa disciplina e da reflexão sobre essa solução. Esses professores participaram de uma experiência formativa em que foram encorajados a resolver um conjunto de tipos de tarefas de geometria dinâmica. Após explorarem o software e as tarefas propostas, os professores elaboraram uma tarefa de cunho investigativo em equipe, dirigida a um público-alvo específico, que propiciasse oportunidades de conjecturar e provar determinada propriedade geométrica usando o software. Analisadas as produções solicitadas, reportaram-se diferentes questões relacionadas com a elaboração da tarefa, entre as quais se destaca que 26 situações abordaram propriedades geométricas e 10 discorreram sobre uma exploração que levasse à formulação e prova de uma conjectura sobre essas propriedades. Em termos de conclusão, as autoras finalizam salientando que, em futuras experiências formativas, deve-se refletir com maior ênfase sobre o tipo de tarefas que permite aproveitar as possibilidades de conjecturar, testar e provar propriedades geométricas que oferecem os SGD para o ensino de geometria.

Bastos, Poffal \& Meneghetti (2015), visando a oferecer uma alternativa de ensino de geometria para o professor de matemática que leciona na Educação Básica, propõem três tarefas ${ }^{4}$ relacionadas ao estudo da circunferência utilizando o software GeoGebra. Essas tarefas foram pensadas para o desenvolvimento de investigações matemáticas na aula (Ponte, Brocardo \& Oliveira, 2003). Desse modo, foram elaboradas para investigar as equações da circunferência, assim como as posições relativas entre circunferências, pontos e retas no plano. Para cada tarefa apresentada e descrita no artigo, os autores incluem os objetivos, os prérequisitos para a resolução, os materiais a serem utilizados, o tempo previsto, as diferentes questões norteadoras e suas soluções correspondentes, assim como algumas dicas para o professor potencializar a orientação do desenvolvimento da tarefa em sala de aula. Para testá-las, os autores aplicaram as tarefas em três turmas de terceiro ano de Ensino Médio e posteriormente modificaram-nas e melhoraram-nas em função dos resultados obtidos após seu desenvolvimento em aula. Os autores finalizam o artigo descrevendo a aplicação das tarefas com os alunos e comentam que a experiência concretizada em aula ajudou, entre outros aspectos, a modificar concepções errôneas dos fundamentos do estudo da circunferência.

Lognoli (2017) propõe três estratégias didáticas para o ensino da área do círculo utilizando o software GeoGebra. As três estratégias baseiam-se em processos de visualização e exploração dos conceitos geométricos envolvidos, estudados previamente com materiais manipulativos. $\mathrm{Na}$ primeira

4 No artigo, os autores utilizam o termo "atividade". Nesta revisão, optou-se pela palavra "tarefa" em vez de "atividade", na medida em que esta última diz respeito a um conceito mais amplo e complexo. 
estratégia, aborda-se a área do círculo como o limite da área de um polígono regular inscrito nele, quando o número de lados do polígono tende a ser grande. Na segunda estratégia, a área do círculo é abordada por meio da transformação dinâmica da sua região interna em uma figura de forma triangular cujo lado maior tem a mesma medida do cumprimento do círculo e cuja altura correspondente a esse lado equivale ao raio do círculo. A terceira estratégia consiste em obter a área do círculo por meio da geração aleatória e uniforme de pontos dentro de um quadrado, circunscrito ao círculo, utilizando o método de Monte Carlo. O autor conclui que o uso do software GeoGebra, mediante as estratégias propostas, pode contribuir para o ensino de geometria na Educação Básica.

Uma sintese integrativa deste primeiro grupo de artigos permite identificar como principal convergência entre eles a presença de tarefas de geometria dinâmica de cunho investigativo para o ensino de geometria na Educação Básica, principalmente nos trabalhos de Scaglia \& Götte (2008) e Bastos, Poffal \& Meneghetti (2015). Esses trabalhos, ao proporem tarefas mediadas por SGD, convergem, pois nelas os professores devem considerar as características, vantagens e potencialidades desses ambientes tecnológicos para possibilitar a realização de investigações matemáticas genuínas e legítimas em um SGD. Embora não explicite o uso de tarefas matemáticas, Lognoli (2017) considera as características de visualização e experimentação dos SGD como aspectos-chave no ensino de objetos geométricos em ambientes tecnológicos, por meio do desenvolvimento de estratégias pedagógicas baseadas na interação. Desse modo, os três artigos dialogam, na medida em que consideram exploração, visualização, conjectura, teste e prova como processos indispensáveis para promover um ensino de geometria em consonância com as características dos SGD, por meio tanto de aplicação de tarefas investigativas quanto de estratégias pedagógicas.

No grupo temático \# 2, relacionam-se os estudos de Andraphanova (2015), Santos-Trigo \& Reyes-Rodríguez (2016) e Poon \& Wong (2017). Eles têm como foco comum as potencialidades dos SGD para o ensino de geometria, com ênfase em tarefas matemáticas, recursos digitais e situações que possibilitam o aproveitamento das vantagens de utilizar esses ambientes tecnológicos em contextos de ensino.

Andraphanova (2015) apresenta o software GeoGebra como um ambiente de geometria dinâmica, que pode ser utilizado para desenvolver processos de visualização e prova de situações que envolvam o uso de transformações geométricas na Educação Básica. Para tal, a autora apresenta uma série de exemplos que ilustram possibilidades de aplicação de transformações geométricas no software. Em cada exemplo, a autora ressalta o que é solicitado, os passos de construção dos objetos geométricos envolvidos, as ferramentas de construção utilizadas, bem como a prova da situação apresentada. A autora conclui que os ambientes de geometria dinâmica como o proposto oferecem a oportunidade de abordar situações matemáticas de uma maneira diferente do modo tradicional ${ }^{5}$, por intermédio do desenvolvimento de visualizações e simulações.

Santos-Trigo \& Reyes-Rodríguez (2016), apoiados na ideia da resolução de tarefas matemáticas, utilizando diferentes vias de solução, como uma oportunidade para desenvolver o pensamento matemático dos alunos, apresentam e discutem diversas soluções para a tarefa de construir um triângulo equilátero com o software GeoGebra. A tarefa foi discutida em um seminário sobre resolução de problemas, do qual participaram oito professores de Educação Básica. As soluções da tarefa surgiram desse seminário, tanto no trabalho presencial quanto na prática proposta pelos professores em outros espaços. Assim, mediante a análise das diferentes soluções para a tarefa de construir um triângulo equilátero, dados um dos seus vértices e a reta que contém os outros dois, identificaram-se diferentes enfoques de solução, categorizados em dois tipos: aqueles que partiram do uso de régua e compasso e aqueles em que foram construídos modelos dinâmicos. Entre outros aspectos, os autores concluem o artigo com uma sugestão de encaminhamento de aprendizagem, composta por cinco passos, para implementar a tarefa em sala de aula: (i) garantir que os alunos compreendam o enunciado da tarefa; (ii) resolver a tarefa usando como ponto de partida o conhecimento geométrico dos alunos; (iii) engajar os alunos em experiências de exploração de objetos dentro dos modelos dinâmicos construídos; (iv) abordar a tarefa a partir de múltiplos focos; e (v) utilizar a informação de cada abordagem da tarefa para realizar perguntas que orientem os alunos em seu processo de resolução.

Poon \& Wong (2017) aplicaram em sala de aula um conjunto de tarefas de geometria dinâmica que envolveram o uso de recursos previamente elaborados com o software GeoGebra, para o ensino de triângulos semelhantes. Os recursos foram construídos para contribuir com o desenvolvimento da visualização de objetos matemáticos na forma de apreensão operativa, segundo a teoria dos registros de representação semiótica de Raymond Duval. As tarefas e os recursos foram aplicados em duas aulas de Educação Básica, das quais participaram 11 alunos, em duas fases: piloto e secundária. $\mathrm{O}$ propósito da primeira fase foi investigar os resultados do uso dos diferentes recursos por parte dos alunos, com o intuito de realizar as melhorias necessárias para utilizá-los novamente na segunda fase.

Entre os resultados obtidos, ressalta-se que alguns dos alunos fornecerem respostas corretas por meio do método de tentativa e erro e não por meio de raciocínio matemático. Também se observa que os alunos não estavam acostumados a envolver-se com tarefas investigativas ou abertas, encontrando dificuldades na sua resolução. Entretanto, constata-se que

5 Refere-se a situações matemáticas em que são usados papel e lápis. 
o uso dos recursos digitais contribuiu para a motivação de aprendizagem dos alunos, nos momentos em que eles usavam o software GeoGebra ativamente para tentar confirmar suas conjecturas durante a resolução das primeiras duas tarefas. Os autores concluem que há a necessidade de estender a pesquisa para um número maior de participantes e publicar a atividade de aula desenvolvida.

$\mathrm{Na}$ sintese integrativa deste segundo grupo de artigos, é possível identificar a presença de tarefas de geometria dinâmica de cunho investigativo como aspectos centrais da atividade desenvolvida em sala de aula, especificamente nos estudos de Poon \& Wong (2017) e Santos-Trigo \& ReyesRodríguez (2016). Por um lado, as tarefas aplicadas por Poon \& Wong (2017), embora não tenham sido o foco principal do seu estudo, constituíram o meio para utilizar os recursos digitais elaborados e, consequentemente, o elemento desencadeador da atividade matemática da aula. Por outro lado, as tarefas apresentadas por Santos-Trigo \& Reyes-Rodríguez (2016), apesar de estarem mais voltadas a processos de construção de figuras geométricas, consideram a exploração e a investigação de regularidades e invariâncias geométricas, ao utilizar modelos dinâmicos criados com SGD como estratégias para a solução dessas tarefas. No tocante a seu estudo, Andraphanova (2015) não explicita o uso de tarefas, mas destaca diferentes situações geométricas que podem ser abordadas em um SGD para favorecer a visualização, o que dialoga com os resultados obtidos por Poon \& Wong (2017) ao utilizarem recursos digitais com alunos da Educação Básica.

Assim, os estudos deste segundo grupo inter-relacionamse, uma vez que, mediante a aplicação de tarefas/situações investigativas mediadas por SGD, é possível a viabilização de experiências de exploração, visualização, conjectura e prova de propriedades em sala de aula. Entretanto, um aspecto que diferencia o estudo realizado por Poon \& Wong (2017) dos outros diz respeito a esses autores considerarem o uso de recursos digitais elaborados previamente, para inseri-los na atividade geométrica da aula. Aliás, destaca-se a sinergia entre esses recursos e as tarefas geométricas implementadas, uma vez que a estrutura e as questões das tarefas fazem sentido quando se utilizam esses recursos. Dessa maneira, as tarefas investigativas aplicadas na aula podem ser potencializadas ao serem elaboradas a partir da inclusão de recursos digitais em consonância com os objetivos a serem atingidos com elas (por exemplo, uma tarefa em que se busque conjecturar e explicar a propriedade de que a soma dos ângulos internos de um triângulo qualquer é igual a $180^{\circ}$ ).

O grupo temático \# 3 relaciona os estudos de Alqahtani \& Powell (2016) e Gómez-Chacón, Romero \& García (2016). Essas pesquisas têm como foco comum a aplicação de referenciais teóricos que envolvem o uso de $S G D$ em contextos de formação continuada de professores e de ensino de geometria na Educação Básica.

Alqahtani \& Powell (2016) investigaram como a apropriação de um ambiente colaborativo de geometria dinâmica, por parte de duas professoras de matemática em formação continuada, contribuiu para o desenvolvimento da sua compreensão geométrica. Baseados na teoria da génesis instrumental, os autores investigaram o processo de instrumentação desenvolvido pelas professoras enquanto se envolviam, de forma colaborativa, na resolução de três tarefas exploratórias e investigativas no ambiente do Virtual Math Teams with GeoGebra (VMTwG). Por meio da análise dos dados, observaram-se aspectos vinculados à apropriação do VMTwG por parte das professoras enquanto interagiam com ele, dentre esses a ação de arrastar de um Ambiente de Geometria Dinâmica (AGD), aplicada de diferentes formas na resolução das tarefas. Os autores salientam que o desenvolvimento da compreensão dessa ação, por parte das professoras, foi uma evidência da sua apropriação do ambiente VMTwG. Logo, a ação de arrastar constitui-se em um aspecto importante da transformação de um AGD em um instrumento da atividade geométrica dos usuários. Os autores concluem seu texto com algumas sugestões de pesquisas sobre outros aspectos relacionados à temática, por exemplo, investigar como professores de matemática implementam AGD de forma colaborativa no momento do ensino.

Gómez-Chacón, Romero \& García (2016) discutem a efetividade da sinergia entre modelos conceituais e metodológicos para compreender a interação entre a cognição e o afeto, na transição entre a gênese instrumental e a discursiva no raciocínio geométrico na resolução de tarefas. Para tal, os modelos de espaços de trabalho geométrico e dimensão instrumental foram utilizados visando descrever a complexidade envolvida na aplicação da tecnologia aos aspectos matemáticos e cognitivos das tarefas. Para atingir o seu objetivo, os autores realizaram um experimento de ensino que envolveu a participação de duas turmas de alunos de Ensino Médio, com o intuito de explorar o efeito de utilizar o software GeoGebra no desenvolvimento de competências e atitudes matemáticas nesses alunos, por intermédio da resolução de duas sequências de tarefas geométricas.

Os resultados da pesquisa mostram, por um lado, que os fatores que afetam a transição da gênese instrumental à discursiva incluem tanto a mediação reflexiva e heurística do professor, no uso do GeoGebra, quanto a atitude matemática dos alunos mediada pelo uso do software. Por outro lado, apontam que a colaboração entre os alunos, mediada pelo software, forneceu-lhes um grau de independência do professor, quem, por sua vez, conseguiu monitorar os processos de pensamento individuais dos alunos mais eficientemente. Os autores concluem discorrendo sobre a necessidade de estender a pesquisa para mais casos, na busca da generalidade dos resultados obtidos.

Uma sintese integrativa deste terceiro grupo de artigos revela, novamente, a presença de tarefas de geometria dinâmica de cunho exploratório e investigativo para o ensino 
de geometria. Em ambos os estudos, as tarefas apresentadas foram recursos metodológicos para atingir um objetivo maior, vinculado à pesquisa de determinado objeto de estudo, por meio da sua análise e interpretação à luz de referenciais teóricos próprios da Educação Matemática. A diferença das investigações dos grupos temáticos anteriores é que as deste grupo são de uma natureza teórica mais explícita, cujos marcos teóricos constituem-se em ferramentas para a interpretação do objeto de estudo pesquisado. Contudo, sublinha-se o papel das tarefas geométricas nas duas pesquisas, uma vez que elas significaram o elemento desencadeador da atividade de seus participantes, principalmente, no estudo de Alqahtani \& Powell (2016). De fato, as tarefas aplicadas neste último trabalho implicaram às participantes oportunidades de envolver-se de forma colaborativa em experiências de exploração, visualização, conjectura e teste de propriedades geométricas no ambiente VMTwG.

Ao longo desta subseção, realizaram-se as sínteses interpretativas e integrativas dos oito artigos correspondentes ao primeiro eixo. Apresenta-se a seguir a sintese da revisão desses artigos, a partir de distintas questões identificadas.

Em primeiro lugar, observou-se um denominador comum nas três sínteses integrativas apresentadas anteriormente: as tarefas de geometria dinâmica de cunho exploratório e investigativo para o ensino de geometria. Ora como aspecto central do estudo, ora como elemento secundário, as tarefas exploratórias e investigativas mediadas por SGD foram um elemento de convergência na maioria dos artigos analisados. Esse fato constitui um indício da tendência relacionada à temática dos SGD, em particular do software GeoGebra, em contextos de ensino de geometria na Educação Básica e de formação continuada de professores de matemática. No que diz respeito aos contextos de ensino na Educação Básica, os estudos levantados salientam as diferentes vantagens de aplicar tarefas investigativas, utilizando o software GeoGebra para desenvolver nos alunos processos de exploração, visualização, construção, conjectura, validação e prova de propriedades de objetos geométricos, bem como o fortalecimento da sua motivação no estudo de geometria. No tocante aos contextos de formação continuada de professores, destaca-se que os docentes se apropriaram do ambiente tecnológico por meio da exploração de tarefas investigativas, com o intuito de utilizálo na sua prática profissional.

Em segundo lugar, percebeu-se a ausência de tarefas propostas em Andraphanova (2015) e Lognoli (2017). Em comparação aos demais artigos analisados, eles não propuseram tarefas de geometria dinâmica específicas que dialogassem com as estratégias de ensino e com as situações apresentadas nesses textos, o que vai de encontro à tendência da literatura especializada comentada anteriormente. Aliás, salienta-se que esses dois artigos são os únicos estudos não empíricos desse primeiro eixo da revisão. Perante essa situação, considera-se importante a indicação de tarefas de geometria dinâmica nesse tipo de artigo (estudos não empíricos) em que se discutam as possibilidades e limitações de implementar essas tarefas, os referenciais teóricos considerados na sua elaboração e o papel do SGD na sua exploração e na sua resolução.

Finalmente, identificou-se a ausência de $\operatorname{estudos}^{6}$ que investigassem os saberes mobilizados por professores que ensinam matemática ao elaborar tarefas de geometria dinâmica de cunho investigativo. Dos artigos revisados, os de Scaglia \& Götte (2008), Alqahtani \& Powell (2016) e SantosTrigo \& Reyes-Rodríguez (2016) são os que correspondem a contextos de formação continuada de professores de matemática. Desses estudos, só o apresentado por Scaglia \& Götte (2008) aproximou-se da temática referida, ao envolver os professores da pesquisa em atividades de elaboração de tarefas investigativas mediadas por SGD para aplicá-las em sala de aula. Porém, os resultados dessa pesquisa evidenciam que muitos desses professores não mobilizaram os saberes necessários para ter sucesso na elaboração das tarefas solicitadas. Embora Santos-Trigo \& Reyes-Rodríguez (2016) descrevam formas de aplicar a tarefa apresentada por eles em sala de aula, considera-se importante que os professores em formação, além de utilizarem tarefas elaboradas por outros, tenham a oportunidade de construir suas próprias tarefas, adaptando-as às suas necessidades, aos seus alunos e aos contextos particulares da sua prática profissional.

Para tal, é imperativo oferecer aos professores contextos de formação continuada em que, indo além de propostas como a de Scaglia \& Götte (2008), tenham a oportunidade de pensar e refletir sobre os saberes necessários para elaborar tarefas de geometria dinâmica de cunho investigativo e, consequentemente, possam desenvolver seu próprio conhecimento em relação a esses saberes.

\subsection{Metassíntese do Eixo 2: "Teacher Knowledge" - Mathematics}

No segundo eixo, foram revisados 13 artigos relacionados com o conhecimento ${ }^{7}$ do professor que ensina matemática. A análise desses artigos permitiu categorizá-los em quatro grupos temáticos (Quadro 3). Considerando essas categorias, apresentam-se as sínteses interpretativas e integrativas correspondentes.

\footnotetext{
6 Convém recordar ao leitor que os resultados reportados nesta revisão estão em função do recorte metodológico apresentado. Assim, quando forem encontradas afirmações sobre a falta de estudos em um tema, deverão considerar-se as escolhas metodológicas da revisão e aquilo que foi deixado de fora em virtude dessas escolhas.

7 Nesta revisão, assumem-se como diferentes os conceitos de saber e conhecimento. A ideia de conhecimento que se utiliza nesta subseção se refere ao conceito de saber, conforme teorizado por Radford (2013). Porém, decidiu-se usar o termo conhecimento nesta subseção para não criar confusão no leitor, considerando que a tradução comum da palavra knowledge ao português é conhecimento.
} 
Quadro 3 - Temáticas dos artigos do Eixo 2

\begin{tabular}{|c|c|c|c|}
\hline Temática do Artigo & Autor(es) do Artigo & Subfoco Temático & Contexto Investigativo \\
\hline \multirow{4}{*}{$\begin{array}{l}\text { 1. Apresentação de referenciais } \\
\text { teóricos e/ou conceituais }\end{array}$} & Ball, Thames \& Phelps (2008) & $\begin{array}{l}\text { Domínios do conhecimento } \\
\text { matemático do professor }\end{array}$ & Pesquisa teórica \\
\hline & Charalambous \& Hill (2012) & $\begin{array}{l}\text { O conhecimento do professor } \\
\text { como instrumento }\end{array}$ & $\begin{array}{l}\text { Ensino de matemática na } \\
\text { Educação Básica }\end{array}$ \\
\hline & Flores-Medrano et al. (2016) & $\begin{array}{l}\text { O papel do conhecimento do } \\
\text { professor no ensino }\end{array}$ & \multirow[b]{2}{*}{ Pesquisa teórica } \\
\hline & Godino et al. (2017) & $\begin{array}{l}\text { Relação entre conhecimento e } \\
\text { competências/habilidades do } \\
\text { professor }\end{array}$ & \\
\hline \multirow{3}{*}{$\begin{array}{l}\text { 2. Exploração do } \\
\text { conhecimento do professor }\end{array}$} & Kontorovich \& Zazkis (2016) & $\begin{array}{l}\text { Conhecimento matemático do } \\
\text { conteúdo do professor }\end{array}$ & \multirow{2}{*}{$\begin{array}{l}\text { Formação continuada de } \\
\text { professores }\end{array}$} \\
\hline & Prado \& Lobo da Costa (2016) & $\begin{array}{l}\text { Tarefas no desenvolvimento do } \\
\text { conhecimento do professor }\end{array}$ & \\
\hline & $\begin{array}{l}\text { Tekin-Sitrava \& Isiksal-Bostán } \\
\text { (2016) }\end{array}$ & $\begin{array}{l}\text { Conhecimento matemático do } \\
\text { conteúdo do professor }\end{array}$ & $\begin{array}{l}\text { Ensino de matemática na } \\
\text { Educação Básica }\end{array}$ \\
\hline \multirow{3}{*}{$\begin{array}{l}\text { 3. Medição do conhecimento } \\
\text { do professor }\end{array}$} & Hill, Ball \& Schilling (2008) & $\begin{array}{l}\text { Domínios do conhecimento } \\
\text { matemático do professor }\end{array}$ & $\begin{array}{l}\text { Formação continuada de } \\
\text { professores }\end{array}$ \\
\hline & Hsieh (2013) & \multirow{2}{*}{$\begin{array}{l}\text { Relação entre conhecimento e } \\
\text { competências/habilidades do } \\
\text { professor }\end{array}$} & \multirow{2}{*}{$\begin{array}{l}\text { Ensino de matemática na } \\
\text { Educação Básica }\end{array}$} \\
\hline & Blömeke et al. (2016) & & \\
\hline \multirow{3}{*}{$\begin{array}{l}\text { 4. Situações de aula } \\
\text { relacionadas com o } \\
\text { conhecimento do professor }\end{array}$} & Hill \& Charalambous (2012) & $\begin{array}{l}\text { O conhecimento do professor } \\
\text { como instrumento }\end{array}$ & \multirow{3}{*}{$\begin{array}{l}\text { Ensino de matemática na } \\
\text { Educação Básica }\end{array}$} \\
\hline & Clark-Wilson \& Noss (2015) & $\begin{array}{l}\text { Relações entre o conhecimento } \\
\text { do professor e as tecnologias } \\
\text { digitais }\end{array}$ & \\
\hline & $\begin{array}{l}\text { Rowland, Thwaites \& Jared } \\
\text { (2015) }\end{array}$ & $\begin{array}{l}\text { Dimensões do conhecimento } \\
\text { matemático do professor }\end{array}$ & \\
\hline
\end{tabular}

Fonte: Dados da pesquisa.

O grupo temático \# 1 relaciona os estudos de Ball, Thames \& Phelps (2008), Charalambous \& Hill (2012), Flores-Medrano et al. (2016) e Godino et al. (2017). Eles têm como foco comum a apresentação de marcos teóricos elou conceituais sobre o conhecimento do professor que ensina matemática, com ênfase nos domínios desse conhecimento, no seu papel no ensino e nas relações com as habilidades do professor.

Ball, Thames \& Phelps (2008) reportam o Conhecimento Matemático para o Ensino (MKT) como um referencial teórico baseado na prática, que informa sobre o conhecimento matemático necessário para ensinar matemática. O MKT foi desenvolvido a partir da noção de conhecimento pedagógico do conteúdo de Shulman, por meio de análises qualitativas (no contexto de um projeto longitudinal) e medidas do MKT baseadas em hipóteses formuladas a priori. Os resultados obtidos permitiram identificar quatro domínios do MKT, nomeadamente, o Conhecimento Comum do Conteúdo (CCK), o Conhecimento Especializado do Conteúdo (SCK), o Conhecimento do Conteúdo e dos Alunos (KCS) e o Conhecimento do Conteúdo e do Ensino (KCT). Provisoriamente, foram incluídos no modelo o conhecimento do currículo e o conhecimento do conteúdo no horizonte.

Os autores concluem reconhecendo três problemas do MKT: (i) o fato de o modelo ter sido desenvolvido na prática e os problemas de variabilidade que isso produz; (ii) a não facilidade de discernir os limites entre os domínios de conhecimento; e (iii) a incerteza de ser um modelo específico ou dependente dos estilos de ensino. Por fim, salientase a importância de realizar pesquisas sobre o SCK para compreender as dimensões mais importantes do conhecimento profissional dos professores.

Charalambous \& Hill (2012) explicitam os referenciais teóricos e metodológicos de um estudo longitudinal, em que se buscava dar conta das contribuições do conhecimento dos professores e dos materiais curriculares para a qualidade do ensino escolar. Quanto ao referencial teórico, os autores utilizaram um modelo em que a qualidade matemática do ensino compõe-se por cinco aspectos, dentre eles: a riqueza das matemáticas ensinadas, a capacidade dos professores de trabalhar as ideias e os erros matemáticos dos alunos, e a participação dos alunos na criação de significados e no desenvolvimento de trajetórias coerentes de ensino. Segundo o modelo teórico, a qualidade matemática do ensino está em função do MKT dos professores e dos Materiais Curriculares (MC), entendidos como as representações das tarefas e conceitos matemáticos a serem abordados. Foram observadas as aulas de nove professores de Educação Básica por um período. A análise foi realizada em várias etapas, que incluíram $\mathrm{o}$ ato de assistir os registros em vídeo das aulas, a descrição dos eventos visualizados, a exploração das contribuições do MKT e dos MC para a qualidade matemática do ensino, a identificação de outras possíveis contribuições e uma análise de casos cruzados.

Flores-Medrano et al. (2016), com o intuito de compreenderem o papel do professor de matemática na 
gestão do trabalho matemático da aula, estabelecem relação entre o modelo Mathematics Teacher'Specialised Knowledge (MTSK) e as diferentes noções do modelo teórico Espaços de Trabalho Matemático (ETM). Assim, são apresentados e discutidos esses referenciais teóricos para o posterior estabelecimento de relações entre ambos os modelos. Por um lado, o MTSK é descrito como um modelo de conhecimento especializado do professor de matemática e explicado em função de domínios e subdomínios do conhecimento do professor. Por outro lado, os ETM são apresentados como um modelo explicativo do trabalho matemático do aluno em um contexto escolar, em função de um modelo que considera aspectos cognitivos e epistemológicos do trabalho do aluno enquanto se envolve em determinada atividade matemática. Finalmente, os autores ressaltam as relações entre ambos os marcos teóricos, por meio de um exemplo em que uma professora de matemática desenvolve com uma turma de alunos um espaço de trabalho matemático sobre os conceitos geométricos de reta, semirreta e segmentos. As decisões da professora no planejamento desse espaço de trabalho, o seu nível de conhecimento sobre o tema e o desenvolvimento da aula são alguns dos fatores sublinhados pelos autores como influentes na criação do espaço de trabalho matemático idôneo em sala de aula.

Godino et al. (2017) apresentam e descrevem um sistema que integra e relaciona as categorias do conhecimento do professor que ensina matemática com suas competências didático-matemáticas no momento de desenvolver sua prática profissional em sala de aula. Para tal, utilizam o Enfoque Ontosemiótico do conhecimento e da instrução matemática (EOS), articulando os conhecimentos e as competências didático-matemáticas do professor. Assim, são apresentadas as cinco noções teóricas do EOS: sistema de práticas, configuração de objetos e processos matemáticos, configuração didática, dimensão normativa e idoneidade didática. A partir disso, os autores descrevem seu próprio modelo de conhecimento do professor que ensina matemática - tomam como referência modelos como o MKT - e posteriormente as competências didáticas específicas do professor, estabelecendo relação entre elas e as noções teóricas do EOS. Finalmente, são ilustradas três ações formativas a modo de exemplo; nelas é aplicado o sistema teórico apresentado para a formação do professor que ensina matemática. Entre as conclusões, os autores salientam que, apesar de o texto ser de natureza teórica, há estudos que reportam investigações empíricas em que é aplicado o sistema teórico apresentado.

Uma sintese integrativa deste primeiro grupo de artigos identifica a tendência dos pesquisadores acadêmicos em considerar marcos teóricos específicos do conhecimento matemático do professor que ensina matemática. Os autores dos quatro artigos convergem na ideia de que o professor, quando desenvolve sua prática profissional, mobiliza um conjunto de conhecimentos específicos e/ou próprios do ensino de matemática, diferentes daqueles que são mobilizados por outro profissional. Esse fato reflete-se no modelo MKT de Ball, Thames \& Phelps (2008), o qual foi considerado por Charalambous \& Hill (2012) no seu estudo e inspirou o modelo desenvolvido por Godino et al. (2017). Apesar de não ser diretamente influenciado pelo MKT, o modelo de conhecimento do professor que ensina matemática de FloresMedrano et al. (2016) dialoga significativamente com o desenvolvido por Ball, Thames \& Phelps (2008), na medida em que ambos os modelos interpretam o conhecimento do professor como específico do trabalho de ensinar matemática em contextos escolares. Em especial, evidencia-se que o modelo MKT está presente em três dos quatro artigos que compõem este grupo temático, o que mostra parcialmente a sua aceitação por parte de educadores matemáticos do campo.

O grupo temático \# 2 está composto pelos estudos de Kontorovich \& Zazkis (2016), Prado \& Lobo da Costa (2016) e Tekin-Sitrava \& Isiksal-Bostan (2016). São três pesquisas empíricas em que se exploram os conhecimentos do professor de matemática em contextos de formação continuada de professores e ensino de matemática na escola.

Kontorovich \& Zazkis (2016), visando a explorar a maneira em que um grupo de 16 professores de matemática lidam com as tensões entre duas perspectivas do ângulo, objetivam caracterizar as aproximações do ângulo empregadas por esses professores como forma estática e rotação dinâmica. Para tal, os professores, em contexto de formação continuada, foram engajados a resolver uma tarefa que solicitava a criação de diálogos hipotéticos entre um docente e estudantes em que se abordasse a conjectura de que a soma dos ângulos exteriores de um polígono é igual a $360^{\circ}$. Por meio de uma análise de conteúdo das produções escritas dos participantes, os autores apresentaram quatro enfoques: (i) a conjectura foi explorada só para famílias de polígonos; (ii) a perspectiva de ângulo como forma foi estendida para medidas negativas; e (iii) ambas as perspectivas do ângulo foram combinadas. Os autores concluem alguns aspectos do estudo, dentre os quais destacam dois. Por um lado, ressalta-se que a maioria dos professores não coordenaram adequadamente as perspectivas do ângulo, realizando combinações delas que levaram a definições não necessárias e não rigorosas. Por outro lado, destaca-se a escrita de roteiros como um ótimo instrumento de produção de dados, na medida em que permite aos participantes prepararem respostas reflexivas sem a pressão de outros procedimentos aplicados em períodos mais reduzidos.

Prado \& Lobo da Costa (2016), com o intuito de compreender as possibilidades das atividades de programação na (re)construção dos conhecimentos necessários para a docência com tecnologias digitais, analisam dois episódios provenientes de dois cursos de formação continuada de professores de matemática em que foram desenvolvidas atividades de programação para atingir determinadas tarefas formativas. Para tal, as autoras utilizam o TPACK como modelo do conhecimento do professor em relação à integração das tecnologias em sala de aula, com o propósito de analisar 
a (re)construção dos conhecimentos dos participantes da pesquisa em virtude dos saberes tecnológicos mobilizados. Em ambos os episódios da formação continuada, os professores participantes conseguiram modificar seus conhecimentos docentes mediante as experiências de envolver-se em atividades de programação - tais como a criação de um botão no software GeoGebra para a exposição de elementos que definem uma simetria axial e a elaboração de um software educativo com Scracth - em que se abordasse o tema das generalizações algébricas mediante sequências numéricas e padrões. Entretanto, observa-se que a segunda atividade de programação se tornou complicada para os professores, sobretudo, no momento de programar o feedback ao usuário, uma vez que, para conseguir isso, devia-se antecipar as respostas dos alunos e programar diferentes tipos de feedback. As autoras concluem que a formação do professor para o uso das tecnologias digitais na perspectiva do TPACK é complexa e de longa duração.

Tekin-Sitrava \& Isiksal-Bostan (2016) objetivam explorar o CK de quatro professores de matemática de Educação Básica ao gerar métodos alternativos de calcular o volume de um prisma. Para a produção dos dados, os autores: (i) aplicaram um questionário em que se solicitava aos participantes explicar os métodos de solução que eles conheciam para calcular o volume de um prisma; (ii) realizaram entrevistas para aprofundar as respostas do questionário; e (iii) fizeram observação direta das aulas dos participantes. Para analisar os dados, utilizaram-se quatro categorias que dizem respeito aos diferentes métodos de cálculo de áreas de prismas: fórmula de volume, contagem sistemática, contagem de camadas e iteração linha-coluna.

Entre os resultados obtidos, reporta-se que os professores propuseram no questionário, pelo menos, dois métodos para calcular o volume de um prisma. Porém, observa-se que os docentes não utilizaram todos os métodos propostos no questionário em suas aulas, predominando o uso da fórmula de volume. Na conclusão, os autores indicam, além de outros fatores, a necessidade de os professores com limitações conceituais participarem de programas de formação continuada para fortalecer o conhecimento dos conteúdos que lecionam em suas aulas.

Uma sintese integrativa dos artigos que compõem este segundo grupo temático permite identificar dois aspectos convergentes. Em primeiro lugar, observa-se a influência do trabalho desenvolvido por Lee Shulman nas pesquisas de Prado \& Lobo da Costa (2016) e Tekin-Sitrava \& IsiksalBostan (2016). Na primeira, as autoras utilizaram o TPACK, modelo desenvolvido a partir do Conhecimento Pedagógico do Conteúdo (PCK). Na segunda, os investigadores utilizaram o CK como base do conhecimento do professor. Entretanto, salienta-se que essas pesquisas, próprias do campo da Educação Matemática, utilizam referenciais teóricos vinculados aos estudos desenvolvidos por Shulman, apesar de existirem modelos específicos do conhecimento do professor que ensina matemática, evidenciados no grupo anterior. Essa questão dialoga com os resultados obtidos por Fiorentini \& Crecci (2017), os quais afirmam que a maioria dos estudos brasileiros de doutorado realizados nos últimos anos sobre o conhecimento do professor que ensina matemática ainda utilizam referenciais teóricos não específicos da Educação Matemática.

Em segundo lugar, destaca-se, nos estudos de Kontorovich \& Zazkis (2016) e Prado \& Lobo da Costa (2016), o uso de tarefas para a mobilização de conhecimentos por parte dos professores que participaram dessas pesquisas. Assim, no primeiro texto, os autores aplicaram a tarefa como um instrumento para explorar o conhecimento geométrico dos participantes. No segundo, as autoras propuseram um conjunto de atividades (entendidas neste artigo como tarefas) para desenvolver o conhecimento tecnológico e pedagógico dos professores em formação. Logo, as tarefas enquanto instrumentos de formação foram fundamentais na realização dessas pesquisas.

No grupo temático \# 3, relacionam-se os estudos de Hill, Ball \& Schilling (2008), Hsieh (2013) e Blömeke et al. (2016). Eles visam a medir aspectos do conhecimento do professor de matemática, em contextos de formação continuada e de ensino de matemática na Educação Básica para atingir determinados objetivos.

Hill, Ball \& Schilling (2008) objetivam conceitualizar e desenvolver medidas do KCS, aquele conhecimento que diz respeito tanto ao conhecimento matemático quanto ao modo como os estudantes pensam ou aprendem esse conhecimento. Para tal, realizaram-se análises psicométricas em um projeto de formação continuada de professores de matemática de Educação Básica. Uma parcela dos integrantes desse curso foi convidada a responder uma série de itens no formato de múltipla escolha e a participar de entrevistas cognitivas. Os itens desenvolvidos foram incluídos em quatro categorias relativas ao trabalho dos alunos em sala de aula, nomeadamente, seus erros comuns, suas compreensões do conteúdo, o desenvolvimento de sequências de trabalho e estratégias comuns de cômputo. Entre os resultados obtidos, as autoras reportam a existência do KCS em muitas das respostas fornecidas pelos participantes. Entretanto, indicam que medir esse conhecimento não é um assunto fácil e que os processos metodológicos seguidos podem ser melhorados/aprofundados. Dentre as conclusões, as autoras sublinham que o KCS, como conhecimento, precisa de mais desenvolvimento, na medida em que se trata de um conhecimento multidimensional.

Hsieh (2013), motivado pela falta de modelos teóricos que interpretem o conhecimento do professor que ensina matemática em países não ocidentais e os correspondentes itens para medir esse conhecimento, introduz o modelo de Competências do Ensino de Matemática (MTC), criado em Taiwan, como um marco que conceitualiza o Conhecimento Pedagógico do Conteúdo Matemático (MPCK) desse professor. Em termos teóricos, o MTC está centrado em três 
objetos: elementos, operações e núcleos. Em suma, o MTC abrange 20 elementos vinculados aos conhecimentos e às competências do professor que ensina matemática e três operações relacionadas com esses elementos: reconhecimento e compreensão, pensamento e raciocínio e execução conceitual. Quanto aos núcleos, o MTC possui três, quais sejam, aprendizagem, ensino e entidade.

Em termos práticos, o MTC foi utilizado para medir o MPCK por meio do reexame e reclassificação dos itens de medição do MPCK utilizados nos estudos internacionais Ensino de Matemática no Século 21 (MT21) e Formação de Professores e Estudo de Desenvolvimento em Matemática (TEDS-M). Entre outras questões, o autor conclui sublinhando a necessidade de serem realizadas pesquisas sobre a identificação e a distinção entre os diferentes tipos de conhecimentos do professor de matemática.

Blömeke et al. (2016) examinam a relação entre o conhecimento e as habilidades de 171 professores de matemática de Educação Básica, baseando-se em um modelo bidimensional que distingue, por um lado, o conhecimento do professor como recursos cognitivos estáveis e generalizáveis, e, por outro, suas habilidades cognitivas como relacionadas com situações de aula mais específicas. Partindo de cinco hipóteses sobre a estrutura da cognição do professor, os autores aplicaram aos participantes da pesquisa 188 provas no formato de papel e lápis e de vídeo, visando a medir as seis componentes do modelo teórico utilizado: Conhecimento do Conteúdo Matemático (MCK), MPCK, Conhecimento Pedagógico Geral (GPK), Habilidades para diagnosticar os erros matemáticos dos alunos (MDiagnose), Habilidades de Instrução Matemática (P-I-D Math) e Habilidades de Gerenciamento da Sala de Aula (P-I-D CM). Entre os resultados obtidos, afirma-se que o modelo teórico vinculado à primeira hipótese se ajustou muito melhor, em comparação com os modelos relacionados com as outras hipóteses. Entre suas conclusões, os autores reconhecem a importância dos resultados obtidos para repensar a formação dos professores e sublinham a necessidade de realizar outras pesquisas que considerem o estudo de outros aspectos da prática do professor, como as suas crenças e as suas motivações.

Fazendo uma sintese integrativa deste terceiro grupo temático, identifica-se um interesse dos autores dos artigos em estabelecer uma relação entre o conhecimento e as habilidades do professor que ensina matemática, sobretudo nos trabalhos de Hsieh (2013) e Blömeke et al. (2016). Embora o modelo proposto por Hill et al. (2008) não enfatize as habilidades do professor, é possível encontrar um ponto comum ao considerar a natureza do KCS do modelo MKT. Segundo as autoras, esse domínio de conhecimento diz respeito, entre outros aspectos, ao conhecimento dos erros comuns que cometem os alunos ao explorar determinado conteúdo matemático. Um ponto de vista particular permitiria relacionar o conhecimento dos erros dos estudantes a certa habilidade do professor, habilidade explícita nos modelos utilizados por Hsieh (2013) e Blömeke et al. (2016). Em ambos os modelos, destaca-se o diagnóstico dos erros dos alunos como uma habilidade específica do professor que ensina matemática. Portanto, a relação entre o conhecimento e as habilidades docentes é um aspecto que vem sendo estudado na Educação Matemática.

O grupo temático \# 4 está composto pelos estudos de Hill \& Charalambous (2012), Clark-Wilson \& Noss (2015) e Rowland, Thwaites \& Jared (2015). Os objetivos deles dizem respeito às relações entre situações de aula especificas e o conhecimento do professor em contextos de ensino de matemática na Educação Básica.

Hill \& Charalambous (2012) discutem os resultados de uma análise de quatro casos cruzados que envolveram a participação de nove professores de matemática de Educação Básica, os quais foram observados por um período enquanto lecionavam aulas dessa disciplina. O objetivo da análise de casos foi dar conta das contribuições, individuais e conjuntas, do MKT desses professores e dos MC na qualidade do ensino escolar. De forma separada, a análise da contribuição do MKT (variável entre os professores participantes) permitiu identificar diferentes aspectos, dentre os quais se destacam o uso denso e preciso de linguagem matemática, de explicações matemáticas, e a conexão de ideias e representações matemáticas. Quanto à contribuição conjunta do MKT e dos $\mathrm{MC}$, os autores reportam que a qualidade do ensino foi alta ou baixa quando os MC forneceram alto ou baixo suporte e quando os professores de alto MKT melhoraram tais materiais. Outro aspecto informado que melhorou a qualidade do ensino foi a disposição ao trabalho dos professores. Dentre as conclusões expostas, os autores salientam que a relação entre o MKT e os MC é direta e interativa, mas que é necessário ampliar as pesquisas sobre essa relação e também sobre a maneira como acontece a aprendizagem profissional dos professores, à medida que essa relação é mobilizada por eles.

Clark-Wilson \& Noss (2015) estendem investigações prévias em que a noção de hiccups (evento contingente) foi estudada em contextos de aulas de matemática mediadas por tecnologias digitais. Assim, por um lado, os autores apresentam sete tipos de hiccups identificados a partir da observação de aulas de matemática em que foi utilizada alguma tecnologia digital. Por outro lado, os autores enfatizam a relação que se estabelece entre o estudo dos hiccups pelos próprios professores em atuação e o desenvolvimento do seu conhecimento profissional, em termos do conhecimento estratégico de Shulman. Após a observação de episódios de aula, são apresentados os sete tipos de hiccups, entre eles estavam os aspectos do design da tarefa, as respostas inesperadas dos alunos ao utilizar a tecnologia, as perturbações vivenciadas pelos alunos ao receber determinado feedback do computador e os problemas de natureza técnica. Em termos de conclusão, há um episódio de formação profissional em que um grupo de professores foi engajado a refletir e agir sobre situações de sala de aula em que o uso de determinada tecnologia digital gerasse possíveis hiccups. As conjecturas 
apontam que professores em formação podem desenvolver seu conhecimento profissional (conhecimento estratégico) à medida que forem envolvidos em situações que lhes permitam identificar e atingir hiccups potenciais da sua própria prática.

Rowland, Thwaites \& Jared (2015) apresentam e descrevem três aspectos que originam os desencadeamentos de eventos contingentes no desenvolvimento de uma aula de matemática de Educação Básica. Esses aspectos representam o avanço dos autores em sua compreensão da quarta dimensão do modelo de conhecimento do professor que ensina matemática, o Knowledge Quartet (KQ), nomeadamente, a contingência. Nesse contexto, os autores apresentam um conjunto de situações, retiradas dos seus dados de pesquisa ao observar um número amplo de aulas de matemática, que revelam a ocorrência destes três desencadeantes de eventos contingentes: quando o professor é confrontado a responder às ideias dos alunos, quando o docente muda o andamento da aula devido ao reconhecimento de determinada situação inadequada para a aula e quando a (in)disponibilidade do uso de recursos didáticos ocorre. Por sua vez, o primeiro desencadeante contingente é composto por três aspectos: a resposta do aluno a uma pergunta do professor, a resposta espontânea de um aluno a determinada atividade ou discussão e a resposta incorreta do aluno. Os autores concluem que, por conta de esses aspectos desencadeantes de eventos contingentes terem sido identificados por meio de estudos empíricos, deve ficar aberta a possibilidade de que outros tipos de desencadeantes emerjam em futuras análises de episódios de sala de aula.

Uma sintese integrativa deste último grupo de artigos revela, mesmo que implicitamente, a presença de tarefas matemáticas na sala de aula como um aspecto convergente dessas pesquisas. No estudo de Hill \& Charalambous (2012), as tarefas matemáticas são um dos elementos que compõem os $\mathrm{MC}$, cuja contribuição à qualidade do ensino de matemática foi analisada. No caso de Clark-Wilson \& Noss (2015), o design das tarefas matemáticas é um fator identificado como possível gerador de eventos contingentes na aula. No texto de Rowland, Thwaites \& Jared (2015), apesar de não se explicitar, certas tarefas matemáticas são exploradas na atividade desenvolvida em aula, nos momentos em que se produzem os eventos contingentes vinculados à resposta espontânea de um aluno a essa atividade. Nesse sentido, os três artigos revelam a importância que possuem as tarefas matemáticas no ensino, uma vez que podem contribuir para sua qualidade ou gerar eventos contingentes para o professor.

Após realizar as sínteses interpretativas e integrativas dos 13 artigos do segundo eixo, apresenta-se uma síntese da revisão desses trabalhos. Em primeiro lugar, destaca-se a presença e influência do modelo MKT de Ball, Thames \& Phelps (2008) no campo da Educação Matemática. No que diz respeito à esta revisão de literatura, dos 13 textos que correspondem com este eixo, 5 assumem esse modelo como referencial teórico para interpretar, analisar e medir o conhecimento que utiliza o professor para desenvolver sua prática profissional. O estudo publicado por Ball, Thames \& Phelps (2008) é citado em grande escala em diversas pesquisas ao redor do mundo. Portanto, trata-se de um dos modelos de conhecimento matemático do professor mais aceitados e difundidos na comunidade internacional da Educação Matemática.

Em segundo lugar, observa-se a ausência de um modelo do conhecimento matemático do professor mediado pelo uso de tecnologias digitais. Nessa temática, as pesquisas de Prado \& Lobo da Costa (2016) e Clark-Wilson \& Noss (2015) são as únicas desta revisão que abordam ou consideram o uso das tecnologias digitais nos seus estudos. Porém, tais investigações não dão conta de um modelo com as características citadas. No caso da primeira, é utilizado o TPACK como modelo de conhecimento, que não é específico do campo da Educação Matemática. No caso da segunda, não se explicita algum modelo específico do conhecimento matemático do professor com tecnologias digitais. Esse resultado convida a refletir sobre a necessidade de ser considerada a possibilidade de pensar um modelo específico como o citado, que permita focar a lente dos pesquisadores que investigam a natureza dos saberes docentes mediados pelo uso de determinada tecnologia digital.

Finalmente, de acordo com o tema deste artigo, encontra-se a ausência de pesquisas cujo objeto de estudo seja os saberes que mobiliza o professor no momento de elaborar tarefas para o ensino. Esses saberes são os que o professor coloca em movimento e utiliza na fase de preparação da aula. Podese perceber na revisão realizada os esforços dos autores em teorizar, explorar e medir diferentes tipos de conhecimentos, tais como o conhecimento do conteúdo e dos erros dos alunos, o pedagógico do conteúdo, aquele manifestado na ocorrência de eventos contingentes, entre outros. Apesar das tarefas matemáticas terem sido identificadas como um dos aspectos convergentes nas sínteses integrativas, não se explora nessas pesquisas a elaboração das tarefas aplicadas por parte dos professores e o saber que estes mobilizaram nessa atividade. Logo, pode-se concluir que o estudo desse conhecimento particular do professor que ensina matemática é um campo aberto de investigação.

\section{Conclusão}

Neste artigo, buscou-se analisar as contribuições da literatura para a elaboração de tarefas investigativas de geometria dinâmica como atividade específica do professor que ensina matemática. Para isso, realizou-se uma metassíntese da literatura contemplando dois eixos vinculados à geometria dinâmica (particularmente o software GeoGebra) e ao saber do professor que ensina matemática.

No primeiro eixo, destacaram-se três aspectos conclusivos. O primeiro deles foi a predominância das tarefas de geometria dinâmica de cunho investigativo no ensino de geometria. Essas tarefas são objetos de discussão em contextos da sala de aula da Educação Básica e em processos formativos, os 
quais visam a melhorar a prática profissional. Também se salientou a ausência de tarefas em pesquisas teóricas com os pressupostos procedimentais e teóricos inerentes à geometria dinâmica, ou seja, $\grave{a}$ especificidade que as tecnologias digitais oferecem em diálogo com as estratégias de ensino. Por último, reportou-se a falta de estudos sobre os saberes mobilizados por professores de matemática ao elaborarem tarefas investigativas de geometria dinâmica.

Da mesma forma, no segundo eixo, evidenciou-se três aspectos conclusivos: (a) presença e influência do modelo MKT no campo da Educação Matemática; (b) a ausência de um modelo do conhecimento matemático do professor mediado pelo uso de tecnologias digitais, uma vez que, geralmente, são adotados estudos vinculados às Ciências da Educação; e (c) $a$ ausência de pesquisas cujo objeto de estudo seja os saberes que mobiliza o professor a elaborar tarefas para o ensino. Nesse segmento, os estudos tiveram como foco a exploração das tarefas e a tipologia do saber do professor.

Tomando os resultados obtidos nessa revisão, colocase em tela perspectivas de estudos futuros. Uma delas é a elaboração de tarefas investigativas de geometria dinâmica pelos professores. Além de utilizarem tarefas elaboradas por outros, indica-se que professores em exercício/formação elaborem suas próprias tarefas, adaptando-as às suas necessidades, aos seus alunos e aos contextos da sua prática.

Outra possibilidade é o uso de pressupostos teóricos e procedimentais de geometria dinâmica. As tarefas de geometria dinâmica necessitam dialogar com os referenciais teóricos considerados na sua elaboração e o papel do SGD na sua exploração e na sua resolução.

Também se recomenda esta temática: a busca de um modelo teórico do saber/conhecimento matemático do professor e as tecnologias digitais. Um modelo com essas características pode contribuir na evidência de aspectos do saber do professor que incorpora tecnologias digitais em sala de aula, assim como em ações de formação continuada e/ou inicial de docentes que ensinam/ensinarão matemática.

Por fim, é necessário estudar os saberes que o professor mobiliza ao elaborar tarefas. Convém focalizar a maneira em que professores, em contextos formativos, elaboram tarefas investigativas de geometria dinâmica de forma conjunta. Da mesma forma, é preciso compreender como docentes mobilizam saberes próprios da sua profissão para tal fim, no intuito de compreender com maior profundidade essa atividade específica do professor que ensina matemática.

\section{Referências}

Alqahtani, M. M. \& Powell, A. B. (2016). Instrumental appropriation of a collaborative, dynamic-geometry environment and geometrical understanding. International Journal of Education in Mathematics, Science and Technology, 4(2), 72-83. doi: 10.18404/ijemst.38054

Andraphanova, N. (2015). Geometrical similarity transformations in dynamic geometry environment GeoGebra. European Journal of Contemporary Education, 12(2), 116-128. doi: https://dx.doi.org/10.13187/ejced.2015.12.116

Ball, D. L., Thames, M. H. \& Phelps, G. (2008). Content knowledge for teaching: What makes it special? Journal of Teacher Education, 59(5), 389-407. doi: https://dx.doi. org/10.1177/0022487108324554

Bastos, D., Poffal, C. \& Meneghetti, C. (2015). Estudo da circunferência no Ensino Médio: Sugestões de atividades com a utilização do software GeoGebra. Ciência e Natura, 37(3), 123-142. doi: https://dx.doi.org/10.5902/2179460X14252

Blömeke, S., Busse, A., Kaiser, G., König, J. \& Suhl, U. (2016). The relation between content-specific and general teacher knowledge and skills. Teaching and Teacher Education, 56, 35-46. doi: http://dx.doi.org/10.1016/j.tate.2016.02.003

Charalambous, C. Y. \& Hill, H. C. (2012). Teacher knowledge, curriculum materials, and quality of instruction: Unpacking a complex relationship. Journal of Curriculum Studies, 44(4), 443-466. doi: http://dx.doi.org/10.1080/00220272.2011.6502 15

Clark-Wilson, A. \& Noss, R. (2015). Hiccups within technology mediated lessons: A catalyst for mathematics teachers' epistemological development. Research in Mathematics Education, 17(2), 92-109. doi: http://dx.doi.org/10.1080/147 94802.2015.1046476

Fiorentini, D. \& Coelho, M. A. V. M. (2012). Aprendizagem profissional de professores em comunidades investigativas. Leitura: Teoria \& Prática, 30(58), 1053-1062.

Fiorentini, D. \& Crecci, V. M. (2017). Metassíntese de pesquisas sobre conhecimentos/saberes na formação continuada de professores que ensinam matemática. Zetetiké, 25(1), 164185. doi: http://dx.doi.org/10.20396/zet.v25i1.8647773

Fiorentini, D. \& Lorenzato, S. (2012). Investigação em educação matemática: Percursos teóricos e metodológicos. Campinas: Autores Associados.

Flores-Medrano, E., Montes, M. A., Carrillo, J., Contreras, L. C., Muñoz-Catalán, M. C. \& Liñán, M. M. (2016). El papel del MTSK como modelo de conocimiento del profesor en las interrelaciones entre los espacios de trabajo matemático. Bolema, 30(54), 204-211. doi: http://dx.doi. org/10.1590/1980-4415v30n54a10

Godino, J. D., Giacamonte, B., Batanero, C. \& Font, V. (2017). Enfoque ontosemiótico de los conocimientos y competencias del profesor de matemáticas. Bolema, 31(57), 90-113. doi: http://dx.doi.org/10.1590/1980-4415v31n57a05

Gómez-Chacón, I. M., Romero, I. \& García, M. (2016). Zig-zagging in geometrical reasoning in technological collaborative environments: A mathematical working space-framed study concerning cognition and affect. ZDM Mathematics Education, 48(6), 909-924. doi: https://dx.doi. org/10.1007/s11858-016-0755-2

Gutiérrez, R. E. \& Pazuch, V. (2019). Tarefas de geometria dinâmica com objetos de aprendizagem para a exploração e a investigação de conceitos geométricos. Boletim GEPEM, (74), 20-36.

Hill, H. C., Ball, D. L. \& Schilling, S. G. (2008). Unpacking pedagogical content knowledge: Conceptualizing and measuring teachers' topic-specific knowledge of students. Journal for Research in Mathematics Education, 39(4), 372400.

Hill, H. C. \& Charalambous, C. Y. (2012). Teacher knowledge, curriculum materials, and quality of instruction: Lessons learned and open issues. Journal of Curriculum Studies, 44(4), 559-576. doi: http://dx.doi.org/10.1080/00220272.2012.71697 
8

Hsieh, F. (2013). Strengthening the conceptualization of mathematics pedagogical content knowledge for international studies: A taiwanese perspective. International Journal of Science and Mathematics Education, 11(4), 923-947. doi: https://doi.org/10.1007/s10763-013-9425-9

Kontorovich, I. \& Zazkis, R. (2016). Turn vs. shape: Teachers cope with incompatible perspectives on angle. Educational Studies in Mathematics, 93(2), 223-243. doi: https://dx.doi. org/10.1007/s10649-016-9699-2

Lognoli, D. (2017). The area of the disk in middle school grade by GeoGebra. International Journal of Emerging Technologies in Learning, 12(11), 28-40. doi: https://doi.org/10.3991/ijet. v12.i11.6834

Ponte, J. P., Brocardo, J. \& Oliveira, H. (2003). Investigações matemáticas na sala de aula. Belo Horizonte: Autêntica.

Poon, K. K. \& Wong, K. L. (2017). Pre-constructed dynamic geometry materials in the classroom: How do they facilitate the learning of 'similar triangles'? International Journal of Mathematical Education in Science and Technology, 48(5), 735-755. doi: https://doi.org/10.1080/002073 9X.2016.1264636

Powell, A. B. \& Pazuch, V. (2016) Tarefas e justificativas de professores em ambientes virtuais colaborativos de geometria dinâmica. Zetetiké, 24(2), 191-207. doi: https://doi. org/10.20396/zet.v24i2.8646517

Prado, M. E. B. B. \& Lobo da Costa, N. C. (2016). O papel da atividade de programação no processo de construção de conhecimentos para a docência. Revista e-Curriculum, 14(3), 898-918.

Radford, L. (2013). Three key concepts of the theory of objectification: Knowledge, knowing, and learning. Journal of Research in Mathematics Education, 2(1), 7-44. doi: http:// doi.dx.org/10.4471/redimat.2013.19

Rowland, T., Thwaites, A. \& Jared, L. (2015). Triggers of contingency in mathematics teaching. Research in Mathematics Education, 17(2), 74-91. DOI: http://dx.doi.or g/10.1080/14794802.2015.1018931

Santos-Trigo, M. \& Reyes-Rodríguez, A. (2016). The use of digital technology in finding multiple paths to solve and extend an equilateral triangle task. International Journal of Mathematical Education in Science and Technology, 47(1), 58-81. doi: https://doi.org/10.1080/0020739X.2015.1049228

Scaglia, S. \& Götte, M. (2008). Una propuesta de capacitación docente basada en el uso de un software de geometría dinámica. Revista Electrónica de Investigación en Educación en Ciencias, 3(1), 35-50.

Tekin-Sitrava, R. \& Isiksal-Bostan, M. (2016). The nature of middle school mathematics teachers' subject matter knowledge: The case of volume of prisms. International Journal of Educational Sciences, 12(1), 29-37. doi: https:// doi.org/10.1080/09751122.2016.11890409

Trocki, A. \& Hollebrands, K. (2018). The development of a framework for assessing dynamic geometry task quality Digital Experiences in Mathematics Education, 4(2-3), 110138. doi: https://doi.org/10.1007/s40751-018-0041-8 